\title{
Vocational Training for Refugees and Sudanese: an institutional set-up for cooperative research
}

\author{
H. W. Schoenmeier
}

\section{Introduction}

Early in 1982 the Socio-Psychological Research Centre on Development Planning (SFE), at the University of the Saar, Saarbruecken, was commissioned to carry out a pre-feasibility study on vocational training for refugees in the Eastern Region of Sudan. This study was to investigate the situation of refugees in the Eastern Region and to find out how the economic situation of refugees could be improved through vocational training. Based on these findings, proposals for a technical assistance project would be designed. ${ }^{1}$

\section{Refugee Situation in the Sudan}

The Sudan is one of the African countries bearing the heaviest refugee burden $\left(671,000\right.$ in September 1983). ${ }^{2}$ In addition to the Southern Sudan with its influx of Ugandan refugees, since 1968 the Eastern Region has experienced several waves of refugees from Eritrea and Ethiopia. As a consequence of famine, revolutionary upheaval and military fighting, almost half a million (465,000 in September 1983) have sought refuge in the Sudan. Hardest hit are the cities in the Eastern Region (Kassala 45,000; Gedaref 30,000; Port Sudan 50,000 ). The social infrastructure, which was already insufficient, cannot stand the new burden. There is neither enough living space nor is there sufficient capacity in hospitals and schools; supplies of food and, even worse, drinking water are in danger, and the number of jobs available is not nearly enough to meet the demand. The resultant increase in the cost of living not only affects the refugees but also the Sudanese from the poorer walks of life, who also have to compete with the refugees for jobs. It is therefore understandable when the open-door policy of the Sudanese Government is criticised. Apart from the economic problems, criticism centres on the negative impact the flood of refugees has on public safety and

For this kind of project on vocational training for refugees, the Government of the FRG had earmarked DM $12 \mathrm{mn}$.

2 Figures taken from the Office of the Commissioner for Refugees (COR). Khartoum on the decay of customs and morals which has resulted. Robberies, public prostitution and illegal consumption of alcohol have been mounting and are attributed to the refugees by the Sudanese.

In an attempt to get a grip on the refugee problems, the Sudanese Government (GoS) has designed a special refugee policy: the National Programme for the Settlement of Refugees (NPSR). This policy is based on the assumption that 'the prevalence of spontaneous settlement has resulted in two main drawbacks. First that pressure on the already overstrained and inadequate services in rural and urban areas has led to friction and resentment, and secondly, that refugees are unable to become self-supporting ...' (National Committee for Aid to Refugees [NCAR 1980, vol I $\sec 2: 6]$. According to the NPSR, the spontaneous settlement of refugees should be discouraged and refugees should be settled in organised settlements in the Eastern Region. About half of the refugee population should live in organised settlements. Up to now some 20 settlements with a total population of $100,000)$ have been established.

Within the NPSR, every settlement is regarded as a development project aiming at the economic selfsufficiency of the refugee inhabitants. The programme is administered by the Office of the Commissioner for Refugees (COR) and mainly financed by UNHCR. The yearly budgets for each settlement include finances for the development of the site, including water supply, construction of huts for the refugees, clearing of farmland, established project administration and communal infrastructure in the field of health and education. Especially in the area of social infrastructure COR cooperates with voluntary agencies, such as the Sudan Council of Churches, British Volunteer Service, Euroaction-Acord, etc. During the initial phase the inhabitants of a settlement receive food from the World Food Program (WFP). This assurance phases out when after some years refugees are expected to have become self-sufficient. 
According to location and economic criteria, three types of settlements have been distinguished:

- rural settlements in which refugees subsist on the produce from small rainfed holdings and supplement their income by rural wage earning employment;

- rural settlement without access to farmland where the refugees have to rely on rural wage labour only;

- urban and semi-urban settlements based mainly on non-agricultural wage labour.

In the different settlements the sources of income vary considerably, but according to NCAR each settlement of 5,000 inhabitants should earn at least $1 \mathrm{mn}$ Sudanese pounds ${ }^{3}$ per year in order to reach selfsufficiency. It is thought that even in rural settlements approximately 15 per cent of this amount should be earned through non-agricultural work. This places the target figure for non-agricultural production in a settlement at 150,000 Sudanese pounds [NCAR 1980, vol II:29], a very high figure for rural settlements in remote areas. Accordingly, vocational training and promotion of crafts and petty industries range high in the priorities of refugee policy.

\section{Labour Market Problems}

Refugees represent a specific minority group whose access to labour is restricted by a number of factors. After an analysis of the different parts of the Sudanese labour market we can summarise:

- Within the formal sector of the labour market, civil service and state-owned corporations are not favourable to refugee employment. On the one hand, entry in this sector is normally restricted to Sudanese nationals, on the other, salaries are very low - about one quarter to one third of what is paid by private employers.

- The privately owned establishments of the formal sector are mainly located in urban areas, especially in and around Khartoum. They offer a variety of jobs open to refugees. Because of the high concentration of these firms in Greater Khartoum they attract many refugees and lead to spontaneous settlement, thereby counteracting the NPSR. In designing development projects this fact should be taken into consideration.

- The majority of the rural refugees have earned their living in the traditional agriculture of Eritrea and Ethiopia as farmers and nomads. The agricultural policy of the COR for the landholding settlements tries to integrate these refugees into modern mechanised agriculture. Whether this policy will be successful or not will influence the number of refugees looking for additional wage labour.

1.3 Sudanese pounds $=$ US $\$ 1$
- Between the modern and the traditional sector of the Sudanese labour market there is a considerable exchange of manpower through migratory labour. For the seventies the figure was estimated at about 1 million, mostly those working in modern agriculture - either in the irrigation schemes or in the rainfed dhurra production around Gedaref.

- The problem of internal labour migration has been aggravated by the increasing labour flow to the oil states. The estimates for this external migration range between 200,000 to 500,000 [ILO 1982:18]. The fact that refugee settlements have been placed in the vicinity of agricultural schemes and around Gedaref may counterbalance the negative effects of the external labour migration on the labour supply of modern agriculture in the Eastern and Blue Nile region.

- The Sudanese informal labour market is important in size and geographical distribution. According to an ILO investigation, about one fourth of all employed in the modern sector of the economy in Greater Khartoum were working in the informal labour market [ILO 1976 and 1978:382]. In the Eastern Region's major towns this figure should be even higher. The conditions prevalent in the informal sector of the economy also favour refugee participation: 1) ease of entry, 2) reliance on indigenous resources, 3) family ownership of enterprises, 4) small scale operations, 5) labour-intensive and adapted technology, 6) skills acquired outside the formal school system, and 7) unregulated and competitive market [ILO 1973:6].

We expect that in addition to the migratory labour in the modern agricultural sector it will be this informal sector of the economy which will provide the majority of jobs for refugees.

\section{Design of a Training Project}

In order to design a training project related to the economic possibilities for refugees two alternatives must be discussed. Alternative one, the establishment of a training centre for a three-year apprenticeship training, is related to the Vocational Training Centers (VTC) run by the Department of Labour and other government departments. They offer within the formal system a three-year apprenticeship training comparable to British or German trades.

Alternative two refers to medium-size training cent res and subcentres for decentralised short term basic training, such as in the Youth Training Centres (YTC) run by the National Council for Sports and Youth Welfare. They offer nine-month basic training courses for men in carpentry, metal work, electricity or building construction, and six-month courses for women in sewing, cloth-painting, handicrafts and 
home economics. In general the courses are part of the non-formal educational system, but for men's courses a certain link to the formal system is feasible.

For a number of reasons [see Schoenmeier 1982:99107] the second alternative was chosen and the YTCP was commissioned by the COR to implement a decentralised training programme in collaboration with the German Volunteer Service. Within the scope of its regular programme for the Sudanese population, the YTCP is to 'provide non-formal education and training in practical skills for economically and educationally disadvantaged young adults . . centres will adapt their programmes to meet the needs and cope with the situation of the target population within their local communities; training programmes will be designed and implemented for helping ... young people towards: i) better employment prospects and income-earning possibilities; ii) increased working productivity; iii) better conditions in the home and family life' [UNDP 1979:4].

In conformity with the political objective that assistance for refugees should also benefit the Sudanese nationals in the 'refugee-affected areas', the infrastructure of the YTCP in the Eastern Region is to be strengthened. At present only main centres in Port Sudan and New Halfa are operating. They should be rehabilitated so that they are able to carry out programmes for both Sudanese and refugees. For the same purpose two additional main centres will be established in Kassala and Gedaref. In all of the main centres, short term, basic training courses will be held for Sudanese and refugees, for men and women, using Arabic and the respective mother tongue as the languages of instruction. In addition to the main centres, sub-centres should be established in refugee settlements. Apart from the training activities, a community-centred economic promotion programme is to support refugees in their efforts to put their vocational skills into actual practice.

Since the economic conditions and the job market in the different refugee settlements and the urban centres of the Eastern Region differ greatly, no standarised training programme can be applied. Instead, individual solutions will have to be found for the different locations. This must be done by means of close cooperation between the COR, the YTCP and representatives of the local communities.

The project will be implemented in two phases. Phase I (lasting two years) is regarded as a developmental phase in which the main centres in Kassala and Gedaref should be planned, sub-centres in the refugee settlements in Abouda and Kashm-el-Girba should be established, and training and trade promotion should be carried out in all of these locations [see Badri 1984].
The experience which can be gathered at Port Sudan, Abouda and Kashm-el-Girba should be sufficient for the extension of the programme into the phase II.

For a systematic programme development and evaluation, a small research and evaluation unit within the project should be formed 'to follow up and recommend alternative solutions to problems that the project might encounter during its operations' [Badri 1984:41].

\section{Research Cooperation}

The main functions of the Research and Evaluation Unit (REU) will be:

- to identify research and evaluation needs within the project in keeping with the perfect goals stated;

- to organise the necessary research and evaluation work. The unit should carry out nothing other than routine research, and delegate more specific research work to external institutions;

- to feed back research and evaluation results to the responsible bodies (Director-General YTC, Supervisory Committee, GTZ) in order to improve decision-making.

The project is a project of technical cooperation between the FRG and the DRS. It is also part of the YTCP-activities. This two fold orientation affects the tasks of the REU. As part of the YTCP, the REU could carry out its tasks according to the normal procedure provided for such a unit within the YTCP. As part of technical cooperation this project is just one example of vocational training in Africa, or an example for the training of refugees. It is in the interest of both parties concerned to evaluate the problems, successes or failures in order to improve the instruments of technical cooperation. But since it is just one example, the experiences it provides must be evaluated in a broader context which goes beyond the actual conditions of this specific Sudanese project.

This could have effects on the position of such a unit within the organisational structure. Since it must serve two different goals, there must be some assurance that both are truly taken into consideration. In the case at hand, the Director-General of YTCP is also to act as project manager of this project. It will therefore be his duty to balance the two.

In the talks which have been taking place concerning the work of the REU, cooperation with external institutions has also been covered. One of the possibilities discussed was the incorporation of institutes of the University of Khartoum, such as the Developmental Studies Research Centre, and German university institutes, such as the Socio-Psychological 
Research Centre on Development Planning. Although cooperation between the project and a Sudanese university institute needs no further justification, the role of the SFE in this cooperation should be clarified.

The participation of a non-Sudanese research institute seems justified, since:

- the project is part of the bilateral technical cooperation between Sudan and the FRG entitling both parties to pursue their legitimate aims and to authorise institutions in which they trust;

- the project has a special target group: refugees and Sudanese in 'refugee-affected areas'; because of the social tensions between the two groups, it might be of advantage for a third party to share in the planning and evaluation work;

- the structural problems of Sudanese research institutions make it difficult to provide the necessary manpower - either for specific topics or for permanent tasks.

Beyond the planning role, the participation of the SFE must also be legitimated:

- the SFE was founded to carry out basic and applied research on questions of social change in Africa and Asia and to assist in the planning, implementation and evaluation of technical assist ance projects;

- the Research Corporation on Educational Assistance formed by the merger of the Research Institute for International Techno-Economic Cooperation and the SFE has been especially engaged in research on technical education. It has been commissioned by the German Ministry for Economic Cooperation with various evaluation studies and the building-up of a planning and evaluation system for all technical training projects sponsored by the Ministry. This research field has been a focus of the research carried out in the Institute for about a decade and has thus contributed considerably to the Institute's experience in vocational training;

- during the last few years the Institute has conducted research on voluntary and involuntary migration, including refugee movements [see Sripraphai and Sripraphai 1982; Goldschmidt 1983; Boesch and Goldschmidt 1984; Schoenmeier 1982, 1983];

- in February 1984, a memorandum of understanding for cooperation in the field of research on psychological aspects of the refugee situation in Sudan was signed by the research council of the COR and the SFE. The corresponding agreement is to be signed in the near future and research cooperation will start in 1984;
- the Sudan Council of Churches is heavily engaged in refugee assistance work. Among its employees, many refugees are working in refugee social services. The Council has applied to German churches for funds which would allow refugees to participate in the research organised by the SFE.

So far the SFE has been accepted as a legitimate partner in the project's field of research and evaluation. The forthcoming negotiations will have to finalise plans for the tasks of the institutions concerned. For the participation of the SFE the following broad areas are relevant:

- research on project-external conditions, such as the educational and occupational aspirations of refugees, relevant for the design of training in the decentralised locations of centres and sub-centres;

- evaluation studies on the effects of the project as an instrument of technical assistance and of basic, low-cost manpower training;

- assistance in setting up the project's in-built planning, implementation and evaluation system;

- assistance in staff development and training.

We expect that solutions can be found which are in the interest of the parties concerned. Up to now efforts have centred on the establishment of common ground and mutual trust. After the original pre-feasibility study in spring 1982, further intensive contacts were established in Khartoum in autumn 1982, spring 1983 and 1984. This is quite intensive, but it seems to be very important for cooperation with African partners that the planning of common research projects is not just routine project-acquisition but signifies a broader, long term interest on the part of the foreign researcher.

\section{References}

Badri, Abdelmoniem, 1982, 'Youth and non-formal education in the Sudan: an assessment and planning model', University of California, Santa Barbara

-1984, Plan of Action: a programme for training Sudanese and Refugees in the Eastern Region of the Sudan, YTCP, Khartoum

Boesch, E. E. and A. M. F. Goldschmidt (eds), 1984, Refugees and Development, Nomos, Baden-Baden

Goldschmidt, A. M. F., 1983, Man in a Changing World an eco-psychological village study east of Mount Kenya, SFE, Saarbruecken

GTZ, 1983, 'Vocational training for refugees and Sudanese nationals in the Eastern Region, Sudan', GTZ, Eschborn

ILO, 1982, Income Generating Activities for Refugees in the Sudan, Geneva, January 
ILO, 1976 and 1978, Growth. Employment and Equity: a comprehensive strategy' for the Sudan, Geneva

National Committee for Aid to Refugees, 1980, Documentation for the 20-23 June Conference, Khartoum 1980, vol I: 'Background and project summaries', vol II: 'Economics and project implementation', vol III: 'Project proposals', Khartoum

Schoenmeier, H. W., 1982, Dezentralisiertes Ausbildung.sund gewerbliches Förderprogramm für Flüchtlinge im Sudan,
Saarbrücken and Eschborn

-1983, Psychological Aspects of the Refugee Situation in Sudan, SFE, Saarbruecken

Sripraphai, P. and K. Sripraphai, 1982, 'Social-psychological determinants of migration tendencies in Thailand', SFE, Saarbruecken

UNDP, 1979, Youth Training Center: revised project document, Khartoum 